\title{
Microfluidic method of viscosity measurement in propane-saturated bitumen
}

\author{
Mira Kim \\ Department of Mechanical Engineering \\ McGill University \\ Montreal, Canada
}

\author{
Nader Mosavat and David Sinton \\ Department of Mechanical Engineering \\ University of Toronto \\ Toronto, Canada
}

\begin{abstract}
In this paper, the viscosity propane-saturated bitumen was measured through a microfluidic chip. Property measurement of propane-saturated bitumen has been traditionally done on a heavy-duty PVT cell, and the application of microfluidics in high temperature and pressure conditions to measure the properties of bitumen is a novel technique. There are two steps in the viscosity measurement of propane-saturated bitumen. First, the propane saturated bitumen is prepared in a high-pressure piston cylinder through propane injection in bitumen at a pressure above its saturation pressure. This propane-bitumen sample is left to saturate till it there is no further pressure drop. Then the propane-saturated bitumen is pushed through the microfluidic chip and the viscosity of the bitumen is measured by the pressure differences and the imaging of the fluid end, as an application of the Poiseuille's law.
\end{abstract}

Keywords-Bitumen, Oil sands, Microfluidics, Propane, PVT, Viscosity, Diffusion

\section{INTRODUCTION}

Steam-assisted-gravity-drainage (SAGD) is a commercially successful oil recovery method for Canadian oil sands, also known as bitumen, by utilizing the heat transfer from steam condensation process to mobilize the highly temperature sensitive bitumen. Solvent-SAGD process is a modification of the SAGD process, where solvents are uses as additional components to reduce the viscosity of bitumen through mass transfer. [1] Vapor extraction technique (VAPEX) is an oil extraction process primarily using the effect of viscosity reduction through mass transfer by injecting light hydrocarbons as propane into bitumen. [2]

As the solvent saturation in bitumen is a crucial part of the VAPEX process, measurement studies to determine the saturation of solvents have been conducted. Pressure-decay method is a popular technique to measure the diffusivity in the gas-liquid systems. [3-7] The first step in the calculation of the diffusivity is to define the appropriate mass-transfer equations. [3] A simplified model of this is the unsteady one-dimensional mass diffusion equation, also known as the Fick's second law of diffusion. Fick's second law of diffusion can be written as below:

$$
\frac{\partial c}{\partial t}=D \frac{\delta^{2} c}{\partial z^{2}}
$$

where $\mathrm{c}$ is the solvent concentration in bitumen, $\mathrm{z}$ is the distance from the bottom of the diffusion cell, and D is the diffusion coefficient of the solvent in bitumen.

The application of Fick's law to the diffusion process in solvent-bitumen has been an interest to many scientists. Tharanivasan et al. [4] published a paper, applying three different boundary conditions to solve this equation. First is the equilibrium boundary condition, where the boundary condition assumes that the heavy oil-solvent interface is saturated with the solvent under the so-called equilibrium at all times. Second is the quasi-equilibrium boundary condition, where the heavy oil-solvent interface is assumed to be saturated with the solvent at the existing pressure in the solvent phase. Third is the nonequilibrium boundary condition, where the solvent mass-transfer flux across the interface is proportional to the difference between the solvent saturation concentration under the equilibrium pressure and the existing solvent concentration at the surface. According to Tharanivasan's paper, the mass transfer across the heavy oilpropane interface is best described by applying the quasiequilibrium boundary condition.

The study of solvent diffusion in bitumen has been conducted using experimental methods as well. Etminan et al. [5] published a paper on the constant pressure technique for gas diffusivity and solubility measurements in heavy oil and bitumen where the boundary conditions were set experimentally to an equilibrium state. This was accomplished by continuously injecting the required amount of gas into the gas cap from a secondary supply cell to maintain the pressure constant at the gas-liquid interface. Additionally, Behzadfar et al. [6] measured the diffusivity of carbon dioxide in bitumen in a pressure-decay method coupled with rheometer. Mixing due to shear imposed by a rheometer allows rapid direct measurement of the equilibrium pressure in the carbon dioxide-bitumen system.

Microfluidics methods of measuring diffusivity has been studied by Fadaei et al. [8] In Fadaei's paper, toluene was injected to a partially bitumen filled microfluidic chip, and one-dimensional diffusion of toluene and bitumen was quantified by through-plane visible-light transmission imaging. Then, by fitting the experimental data to the concentration profiles obtained using a numerical model, diffusion transport dynamics were quantified. The results showed that for intermediate toluene-mass fractions (0.2-0.8), a constant diffusion coefficient of $2.0 \times 10^{-10} \mathrm{~m}^{2} / \mathrm{s}$ was measured. However, at low toluene mass fractions $(<0.2)$, 
significantly reduced diffusive transport was observed, and endpoint analysis indicated diffusion coefficients trending towards $4.3 \times 10^{-11} \mathrm{~m}^{2} / \mathrm{s}$. At high toluene mass fractions $(>0.8)$, the values trend towards $1.5 \times 10^{-10} \mathrm{~m}^{2} / \mathrm{s}$.

Fadeai et al. [9] also measured the diffusivity of bitumencarbon dioxide by using a cross-channel glass microfluidic chip. The device was initially filled with carbon dioxide at low pressure $(<1.0 \mathrm{bar})$. A plug of bitumen was injected into the central $(50 \mu \mathrm{m}$ wide and $20 \mu \mathrm{m}$ deep) channel and subsequently exposed to high-pressure carbon dioxide on both ends. One-dimensional oil swelling in response to carbon dioxide diffusion was imaged over time. A simple mathematical approach was applied to calculate the diffusion coefficient based on the oil-swelling data. Measurement results are reported here at a range of pressures (1-5 MPa) and room temperature $\left(21{ }^{\circ} \mathrm{C}\right)$. The measured diffusion coefficients in this range are on the order of $10^{-10} \mathrm{~m}^{2} / \mathrm{s}$, in good agreement with the relevant published data using conventional methods. The biggest advantage of this method was that it required up to $10 \mathrm{~min}$ of time and a $1 \mathrm{~nL}$ plug of sample in comparison with conventional methods that require hours or days and up to $0.5 \mathrm{~L}$ of sample.

In this paper, measurement of bitumen viscosity with propane saturation was conducted using a microfluidic method. Though viscosity measurement through a microfluidic device has been previously done in biological research, [10-13] the property measurements of solvent saturated bitumen have traditionally been done in macroscale experimental apparatus. [14-22] The use of the glass microfluidic chip in this work allows experiments to have advantages in sample size reduction and miniaturization of system design, bringing the heavy-duty petroleum PVT research on lab-on-a-chip scale.

\section{EXPERIMENTAL METHOD}

The preparation of propane saturated bitumen was done on a high-pressure piston cylinder. Bitumen was filled in one end of the cylinder and water was filled on the other side. Then a certain volume quantity of liquefied propane was injected to the bitumen filled cylinder. Liquefied propane was used to quantify the amount of mass fraction in bitumen. Propane gas was liquified by drawing propane gas from the cylinder tank (Praxair) to a high-pressure syringe pump (ISCO 100D), and compressing the gas in the high-pressure syringe pump. Then the propane was injected to the bitumen filled side of the piston cylinder at a pressure quite above the saturation pressure, so that the propane saturation in bitumen could be achieved. Pressure was measured after the propane was injected in bitumen, and saturation was determined when the pressure drop was below the accuracy of the pressure gauges $( \pm 1 \mathrm{kPa})$. The pressure drop rate showed a gradual decrease until eventually there was no pressure further pressure drop. The theoretical saturation pressure values were derived from equality of fugacity between the liquid and vapor phases. If the vapor phase is pure propane, the equation for the saturation pressure $\mathrm{P}$ is

$$
\mathrm{P}=\mathrm{x}_{\mathrm{ca}} \mathrm{Y}_{\mathrm{ca}} \mathrm{P} v_{\mathrm{ca}}
$$

where $\mathrm{Pv}_{\mathrm{ca}}$ is the vapor pressure of propane in $\mathrm{kPa}$, and $\gamma_{\mathrm{cg}}$ is the activity coefficient of propane in bitumen. According to literature, the best fit value of the activity coefficient was 1 . 158. This equation primarily indicates that higher pressure is needed to achieve a higher volume fraction of saturation. [2] Figure 1 shows the experimental setup to prepare the propanesaturated bitumen with the thought of connecting it to the microfluidic chip after the saturation. A high-pressure valve was used to close the system after the injection of propane to later connect it to the microfluidic chip.

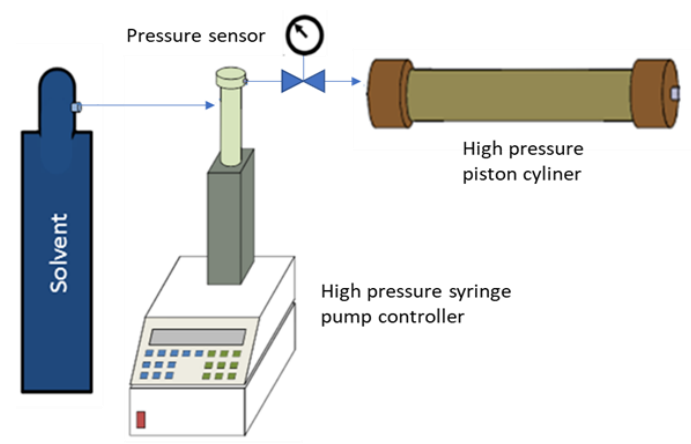

Fig. 1 Setup for propane saturation in bitumen

After the propane saturated bitumen sample was prepared, it was pushed to go through the microchannel in the microfluidic chip. The hydraulic diameter of the microfluidic chip was calibrated to be $76 \mu \mathrm{m}$ by reading the pressure and flowrate of a calibration fluid. The propane bitumen sample was pushed by applying a constant pressure on the other end of the cylinder by the ISCO pump. The pressures were 1.5 and 1.7 MPa, both values above saturation pressures. Poiseuille's law was used to measure the viscosity of the solvent-saturated bitumen through imaging the flow. Poiseuille's law is describe as below

$$
\frac{\mathrm{dx}}{\mathrm{dt}}=\frac{\Delta \mathrm{Pr}^{4}}{8 \mathrm{r}^{2} \mu \mathrm{x}}
$$

where $\mathrm{x}$ is the length of the fluid, $\mathrm{r}$ is the tube radius, $\mu$ is the viscosity of the fluid, and $\Delta \mathrm{P}$ is the total effective pressure. Figure 2 depicts the experimental setup for the viscosity measurement of propane saturated bitumen. 


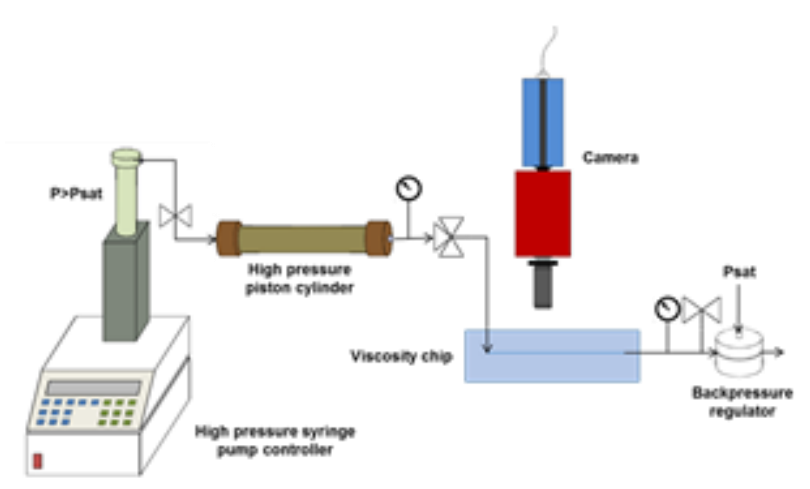

Fig. 2 Schematic for the viscosity measurement of the propane-saturated bitumen.

The experimental conditions of the two runs are summarized in Table 1. The propane fraction values were selected to compare a higher propane fraction ratio to a lower propane fraction ratio with the objective to demonstrate the effectiveness of solvent saturation in bitumen viscosity reduction.

Table 1 Experimental conditions and the measured viscosities for viscosity measurement of propane-saturated bitumen

\begin{tabular}{|c|c|c|c|c|c|}
\hline Run\# & $\begin{array}{c}\text { Bitumen } \\
\text { mass(g) }\end{array}$ & $\begin{array}{c}\text { Propane } \\
\text { mass } \\
\text { fraction }\end{array}$ & $\begin{array}{c}\text { Temperat } \\
\text { ure } \\
\left({ }^{\circ} \mathbf{C}\right)\end{array}$ & $\begin{array}{c}\text { Pressure } \\
(\mathbf{M P a})\end{array}$ & $\begin{array}{c}\text { Measured } \\
\text { Viscosity } \\
(\mathbf{c P})\end{array}$ \\
\hline $\mathbf{1}$ & 2.83 & 0.10 & 20 & 1.5 & 65,000 \\
\hline $\mathbf{2}$ & 2.83 & 0.25 & 20 & 1.7 & 565 \\
\hline
\end{tabular}

\section{RESULTS AND DISCUSSIONS}

In this section, two runs were done with different mass fractions of propane in bitumen. The experiments were captured using a video camera, and the video file was converted using a video to image converter. Figure 3 shows the movement of the bitumen in the first run by putting it into a sequence of frames in a time frame of frame per 10 seconds.
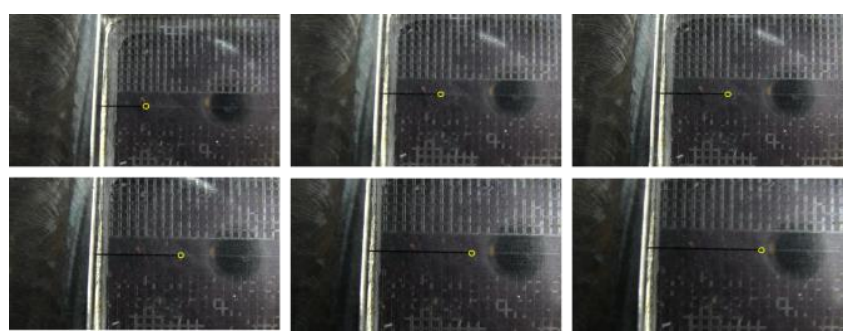

Fig. 3 Sequence of images of run \#1 in every 10 seconds.

Figure 4 is an image capture from the higher propane mass fraction component run. The images were extracted to be $1 / 3$ second per frame from the video to image converter.

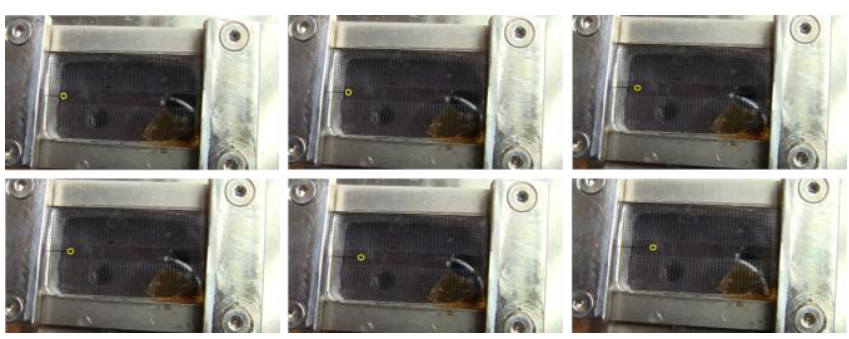

Fig. 4 Sequence of images of run $\# 2$ in every $1 / 3$ second.

Figure 5 shows a comparison of run $\# 1$ and run \#2 in a fuller time frame. Run \#1 had a significantly slower advancement in the flow, and it took 8-9 minutes for the propane-saturated bitumen sample to completely fill the channel. In run \#2, the propane saturated bitumen sample filled the channel in just 7 seconds, resulting in flow speed 2 order of magnitude higher than of run \#1, indicating a significantly lower viscosity. a)

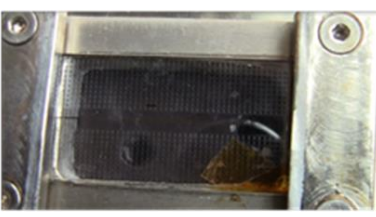

Time $=26 \mathrm{sec}$

b)

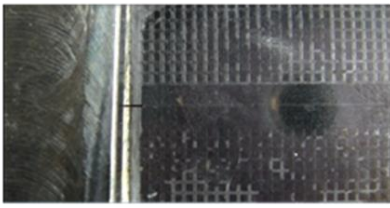

Time $=1 \mathrm{sec}$

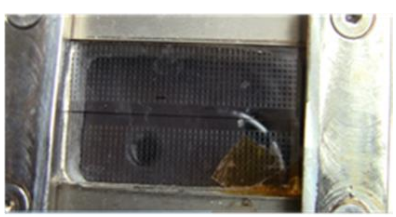

Time $=8 \operatorname{mins} 16 \mathrm{sec}$

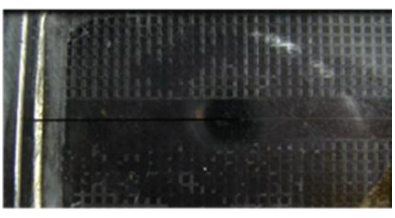

Time $=5 \mathrm{sec}$
Fig. 5 Images of propane-bitumen flow captured at different times during a) run $\# 1$ and b) run $\# 2$.

These images were converted manually into two datasets by calculating the distance of the bitumen front advancement. The grids in the microfluidic chip was a useful standard for this calculation, each grid providing a $1 \mathrm{~mm}$ scale. Then, an excel linear curve fitting function was used to calculate the slope of the plots, and through the calculated linear constant, the viscosity was calculated. Figure 6 shows the graphs depicting the location of the bitumen front in time.
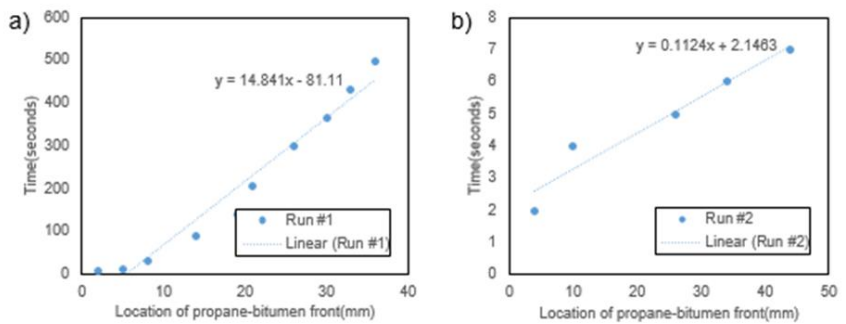

Fig. 6 Location of propane-bitumen flow front and time for a) run $\# 1$, and b) run $\# 2$. 
While the viscosity measurement of solvent-saturated bitumen is still under study, various numerical methods have been developed to estimate the viscosity of bitumen. Here, the measured viscosity was compared with the modified Shu correlation equation. The modified Shu equation for the mixture is:

$$
\begin{gathered}
\mu=\mu_{\text {Bit }}^{x_{\text {Bit }}} \times \mu_{g}^{x_{g}} \\
x_{\text {Bit }}=\frac{\alpha V_{\text {Bit }}}{\alpha V_{\text {Bit }}+V_{g}} \\
x_{g}=1-x_{\text {Bit }} \\
\alpha=\frac{0.000375 \Delta \rho^{-8.56659} \rho_{\text {Bit }}^{456001} \rho_{g}^{-5.27094}}{\ln \left(\mu_{\text {Bit }} / \mu_{g}\right)}
\end{gathered}
$$

where $\mu$ is the viscosity of the mixture, $V_{\text {Bit }}$ is the volume fraction of bitumen, $V_{g}$ is the volume fraction of solvent. The original equation for $\alpha$ is an empirical estimate based on 17 different crude oil and solvents. [22] The $\alpha$ for the Shu equation was modified for propane-saturated bitumen, as it was found that the original empirical estimate by Shu was not appropriate for liquified propane. [2] Furthermore, in this equation, the viscosity estimate was very parameter sensitive, and it is fair to say that an exact analytical solution for the viscosity of the propane-saturated bitumen does not exist, due to the multi-component structure of bitumen, and especially with its asphaltene components. Nevertheless, it is possible that some escape of propane gas and asphaltene deposition during the run could have resulted in a higher viscosity measurement than its actual viscosity.

Figure 7 depicts a graph of the Shu equation and the measured viscosity values. The line depicts the Shu equation and the red points are the measured values.

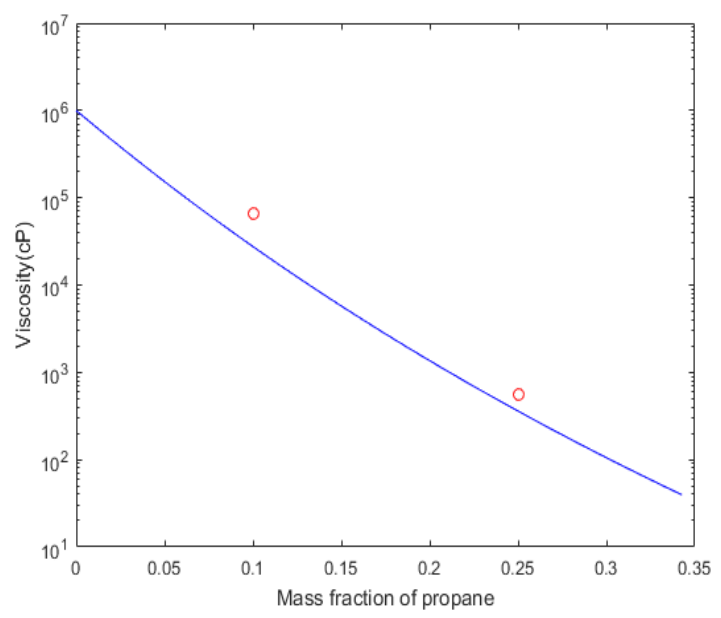

Fig. 7 Viscosity of propane-saturated bitumen through the Shu equation and experimental values. The line indicates the Shu equation and the red points are the measured values.

\section{CONCLUSION}

In conclusion, viscosity measurements of propane-saturated bitumen showed a significant improvement in viscosity reduction. This indicates the effectiveness of the alternative method of viscosity reduction through mass transfer as a comparable method or combined method to viscosity reduction through heat transfer. Additionally, the application of microfluidics was important because it brought visualization of the sample flow, reduction of sample size, and miniaturization of the experimental setup.

Furthermore, this shows that microfluidics can be applied for PVT measurements in petroleum research. An important tool of the PVT measurements in petroleum research is a piston cylinder, and a development of a microfluidic piston cylinder that is capable of withstanding the conditions required for petroleum research, such as high temperature and pressure conditions, [23] and compatibility to harsh solvents would be the next possible direction to bring the heavy-duty petroleum research system to lab-on-chip scale.

\section{ACKNOWLEDGMENT}

Suncor Energy Services is gratefully acknowledged for providing financial support.

\section{REFERENCES}

[1] Kim, Mira. "In-Situ Visualization of Steam Assisted Gravity Drainage with Chemical and Solvent Additives." PhD diss., University of Toronto (Canada), 2017.

[2] Badamchi-Zadeh. A., Yarranton, H. W., Svrcek, W. Y. "Phase Behaviour and Physical Physical Property Measurements for VAPEX Solvents: Part I. Propane and Athabasca Bitumen." J. Can. Pet. Tech. vol. 48, pp. 5461, 2009.

[3] Upreti, Simant R., and Anil K. Mehrotra. "Experimental measurement of gas diffusivity in bitumen: results for carbon dioxide." Ind. Eng. Chem. Res. vol. 39, pp. 10801087, 2000.

[4] Tharanivasan, Asok Kumar, Chaodong Yang, and Yongan Gu. "Measurements of molecular diffusion coefficients of carbon dioxide, methane, and propane in heavy oil under reservoir conditions." Energy Fuels vol. 20, pp. 2509-2517, 2006.

[5] Etminan, S. Reza, Brij B. Maini, Zhangxin Chen, and Hassan Hassanzadeh. "Constant-pressure technique for gas diffusivity and solubility measurements in heavy oil and bitumen." Energy Fuels vol. 24, pp. 533-549, 2010.

[6] Behzadfar, Ehsan, and Savvas G. Hatzikiriakos. "Diffusivity of CO2 in bitumen: Pressure-decay measurements coupled with rheometry." Energy Fuels vol. 28, pp. 1304-1311, 2014.

[7] Das, Swapan K., and Roger M. Butler. "Diffusion coefficients of propane and butane in Peace River bitumen." Can. J. Chem. Eng. vol. 74, pp. 985-992, 1996.

[8] Fadaei, Hossein, John M. Shaw, and David Sinton. "Bitumen-toluene mutual diffusion coefficients using microfluidics." Energy Fuels vol. 27, pp. 2042-2048, 2013.

[9] Fadaei, Hossein, Brent Scarff, and David Sinton. "Rapid microfluidics-based measurement of $\mathrm{CO} 2$ diffusivitv in bitumen." Energy Fuels vol. 25, pp. 4829-4835, 2011.

[10] Kamholz, A. E., Bernhard, H. W., Finlayson, B. A., Yager, P. "Quantitative Analysis of Molecular Interaction in a Microfluidic Channel: The T-Sensor." Anal. Chem. vol. 71, pp. 5340-5347, 1999.

[11] Kang, Y. J. Yoon, S. Y. Lee, K. H. Yang, S. "A Highly Accurate and Consistent Microfluidic Viscometer for Continuous Blood Viscosity Measurement." Artif. Organs vol. 34, pp. 944-949, 2010. 
[12] Silber-Li, Z. H. Tan, Y. P. Weng, P. F. "A microtube viscometer with a thermostat." Exp. Fluids vol. 36, pp. 586-592, 2004.

[13] N. Srivastava and M. A. Burns, "Analysis of NonNewtonian Liquids Using a Microfluidic Capillary Viscometer." Anal. Chem. vol. 78, pp. 1690-1696, 2006.

[14] Kariznovi, M., Nourozieh, H., Abedi, J. "Experimental apparatus for phase behavior study of solvent-bitumen systems: A critical review and design of a new apparatus." Fuel vol. 90, pp. 536-546, 2011.

[15] Nourozieh, H., Kariznovi, M., Abedi, J. "Physical Properties and Extraction Measurements for the Athabasca Bitumen + Light Hydrocarbon System: Evaluation of the Pressure Effect, Solvent-to-Bitumen Ratio, and Solvent Type.” J. Chem. Eng. Data vol. 56, pp. 4261-4267, 2011

[16] Fu, C. T., Puttagunta, V. R., Vilcsak, G. "Gas solubility of methane and ethane in Cold Lake bitumen at in situ conditions." J. Can. Pet. Tech. vol. 27, 1988.

[17] Jacobs F. A. \& Donnelly, J. K. "Viscosity of gas saturated bitumen." Can. Pet. Sci. Tech. vol. 19, pp. 46-50, 1980.
[18] Svrcek, W. Y. \& Mehrotra, A. K. "Properties of Peace River bitumen saturated with field gas mixtures." Can. Pet. Sci. Tech. vol. 28, pp. 50-56, 1989.

[19] Sayegh, S. G., Rao, D. N., Kokal, S., Najman, J. "Phase behaviour and physical properties of heavy oil of linbergh heavy oil/CO2 mixtures." Can. Pet. Sci. Tech. vol. 29, 1990.

[20] Mehrotra, A. K., Eastick, R. R., Svrcek, W. Y. "Viscosity of Cold Lake bitumen and its fractions." The Can. J. Chem. Eng. vol. 67, pp. 1004-1009, 1989.

[21] Svrcek, W. Y. \& Mehrotra, A. K. "Gas solubility, viscosity and density measurements for Athabasca bitumen.” J. Can. Pet. Tech. vol. 21, pp. 31-38, 1982.

[22] Shu, W. R. "A viscosity correlation for mixtures of heavy oil, bitumen, and petroleum fractions." Soc. Pet. Eng. J. vol. 24, pp. 277-282, 1984

[23] Hasselbrink, Jr. E. F., Shepodd T. J., Rehm, J. E. “HighPressure Microfluidic Control in Lab-on-a-Chip Devices Using Mobile Polymer Monoliths." Anal. Chem. vol. 74, pp. 4913-4918, 2002. 